\title{
Effect of High Density Polyethylene (HDPE) on Structural and Optical Properties of (PP/PMMA) Blends
}

\author{
Majeed Ali Habeeb, Ahmed Hamza Abbas
}

Babylon university, College of Education for pure Science, Department of physics, Iraq

E-mail: majeed_ali74@yahoo.com, ahmedalgrabi@yahoo.com

Keywords: Polymer blend, PP/PMMA, Optical properties, Structural properties.

\begin{abstract}
In the present work, Polypropylene (PP) was blended with poly methyl methacrylate (PMMA) to form (PP/PMMA) polymer blends. High Density Polyethylene (HDPE) was mixed into these blends at different weight fractions $(2,4,6,8) \% \mathrm{wt}$ to form (PP/PMMA/HDPE) blends were prepared using an one screw extruder. results obtained from Scanning Electron Microscopy (SEM) revealed that there was a reduction in surface roughness any decrease in clusters, drilling and bends, as for Fourier Transform Infrared (FT-IR) spectrometry showed no change in the wave numbers of the functional groups. The optical properties of samples are investigated by measuring optical absorption spectra in the wavelength range from 260 to $1100 \mathrm{~nm}$. this results show that $\mathrm{E}_{\mathrm{g}}$ of the blends increases with increasing high density polyethylene contents, the indirect optical band gaps for (PP/PMMA) and (PP/PMMA/HDPE) blends were estimated to be about 2.83,2.9,2.95,3and $3.1 \mathrm{eV}$ for indirect allowed transitions, whereas the indirect forbidden band gaps were determined as 2,2.1,2.15,2.2 and $2.3 \mathrm{eV}$ with increase high density Polyethylene contents, respectively. The absorbance, absorption coefficient, extinction coefficient and the imaginary dielectric constant of (PP/PMMA/HDPE) decreases with increasing of HDPE percentages except the transmittance, refraction index and real part of the dielectric constant increase with increasing of high density polyethylene.
\end{abstract}

\section{INTRODUCTION}

Polymer blend represents very important field in processing of new materials which has better properties in comparison with the net polymers. They are significant also from ecological and economical viewpoint[1]. Therefore the polymer blend can be defined as the mixture which has no covalent bonds between components[2]. Polymer blends can be characterized by their phase behavior as being either miscible or immiscible. Immiscible blends show multiple amorphous phases while the miscible blend has only one amorphous phase[3]. Polypropylene (PP) is one of the most important commodity polymers and is used in many areas, such as home appliances, automotive parts, construction and other important industrial applications. PP's applications are often limited due to its low impact strength and Young's modulus properties, particularly at low temperatures and high temperature loading conditions. Blending PP with different polymers is an economic and effective way to improve these drawbacks[4,5]. Polymethyl methacrylate is highly transparent plastic with good mechanical strength and is used variously from commodities to industrial applications. Accordingly, the PMMA is a candidate substrate for optical and medical applications [6,7] as bone cement, dialyser, scaffolds for tissue engineering and potential candidate to waveguide production[8]. The polymer has very good optical properties but has poor scratch resistance. It has good dimensional stability due to rigid polymer chains. It has good weather resistance, and is stable to acid and alkalis. It is attacked by several organic solvents, and has good impact strength higher than that of glass or polystyrene[9]. It has the best transparency and optical properties of commercially available thermoplastic. It is colorless with a $92 \%$ light transmission, an index of refraction of 1.49. It comes in a full range of transparencies. Some of its applications are lenses, outdoor lighting, and indoor lighting[10,11]. High density polyethylene (HDPE) is the highest-volume polymer in the world[12]. HDPE resins have linear molecular chains with comparatively few side chain branches, the chains are packed more closely together. The results are crystalline up to 95 percent and densities ranging from $(0.94$ to 0.96$) \mathrm{g} / \mathrm{cm}^{3}[13]$. 


\section{EXPERIMENTAL}

\section{Preparation of (PP/PMMA/HDPE) Blends}

The Preparation of polymeric mixtures have been using an one screw extruder. The extrusion method was used to different sample prepare which includes polymeric grained smelting and converted to homogeneous fusible by mixing and heating, Then pumping the molten Through the configuration nozzle "Die" to structures formation with cylindrical shape, thereafter cooled by water basin. The extrusion zone temperature ranged from 210 to $250{ }^{\circ} \mathrm{C}$ and a screw speed of 13 rpm was used (the mixing time is less than $40 \mathrm{~min}$. After that, samples cutting in engineering workshop the samples of thickness $(2 \mathrm{~mm})$ and diameter $(2.5 \mathrm{~cm})$.

\section{Theoretical}

The relationship between incident intensity and penetrating light intensity is given by Equation1[14]:

$$
I_{T}=I_{o} \exp \left(-\alpha t_{t}\right)
$$

Where $t_{t}$ is the thickness of matter $(\mathrm{cm})$ and $\alpha$ is the absorption coefficient $\left(\mathrm{cm}^{-1}\right)$.

$2.303 \log (1 / T)=\alpha t_{t}$

$\mathrm{A}=\log (1 / \mathrm{T})$

The absorption coefficient can be calculated by:

$\alpha=(2.303 \mathrm{~A}) / \mathrm{t}_{\mathrm{t}}$

If the amount of absorption is $\left(1 \mathrm{~cm}^{-1}<\alpha<10^{4} \mathrm{~cm}^{-1}\right)$, the electronic transitions are indirect. The amount of optical energy gap from this region can be evaluated by the relation[15]:

$\alpha h v=B\left(h v-E_{g} \pm E_{p h}\right)^{r}$

Where $h v$ is the photon energy, $B$ is the proportional constant, $E_{g}$ is the allowed or forbidden energy gap of indirect transition, $\pm E_{p h}$ is the emission or absorption phonon energy and $\mathrm{r}$ is a constant.

The complex refraction index consists of real and imaginary parts:

$\mathrm{n}^{*}=\mathrm{n}-\mathrm{i} \mathrm{k}_{\mathrm{o}}$

The relation between reflectivity and refractive index is given by Equation [16]:

$\mathrm{R}=\frac{(\mathrm{n}-1)^{2}+\mathrm{k}_{\mathrm{o}}^{2}}{(\mathrm{n}+1)^{2}+\mathrm{k}_{\mathrm{o}}^{2}}$

If $\left(\mathrm{k}_{\mathrm{o}}=0\right)[17]$

$\mathrm{n}=\frac{1+\sqrt{\mathrm{R}}}{1-\sqrt{\mathrm{R}}}$

The extinction coefficient can be calculated by using Equation [18]:

$\mathrm{k}_{\mathrm{o}}=\alpha \lambda / 4 \pi$

Where $\lambda$ is the wavelength of the incident ray. 
The relation between the complex dielectric constant and the complex refractive index $\left(\mathrm{n}^{*}\right)$ is expressed by:

$\varepsilon_{\mathrm{r}}=\left(\mathrm{n}^{*}\right)^{2}$

It can be concluded that[19]:

$\varepsilon_{1}-\mathrm{i} \varepsilon_{2}=(\mathrm{n}-\mathrm{ik})^{2}$

The real and imaginary complex dielectric constant can be expressed by Equations 12 and 13 respectively:

$\varepsilon_{1}=\left(\mathrm{n}^{2}+\mathrm{k}_{\mathrm{o}}{ }^{2}\right)$

$\varepsilon_{2}=2 \mathrm{nk}_{\mathrm{o}}$

\section{RESULTS AND DISCUSSION}

\section{Scanning Electron Microscopy (SEM)}

SEM images were taken to study the morphology of (PP/PMMA) blends with or without HDPE and compatibilizer. The measurements demonstrated a high degree of interoperability between the polymeric mixtures. Figure (1-a) show that the basis material its density random spread, leading to the emergence of clusters, drilling and bends heterogeneous, but when adding a few concentrations of high-density polyethylene to mix observe a decrease in surface roughness any decrease in clusters drilling and bends, and it attributed the decline because of the structural nature of linear chains consisting of (HDPE)[20,21]. This can be seen clearly decreasing at successive concentrations $(2,4,6,8) \% \mathrm{wt}$ in figures $(1-\mathrm{b}, 1-\mathrm{c}, 1-\mathrm{d}, 1-\mathrm{e})$ respectively.

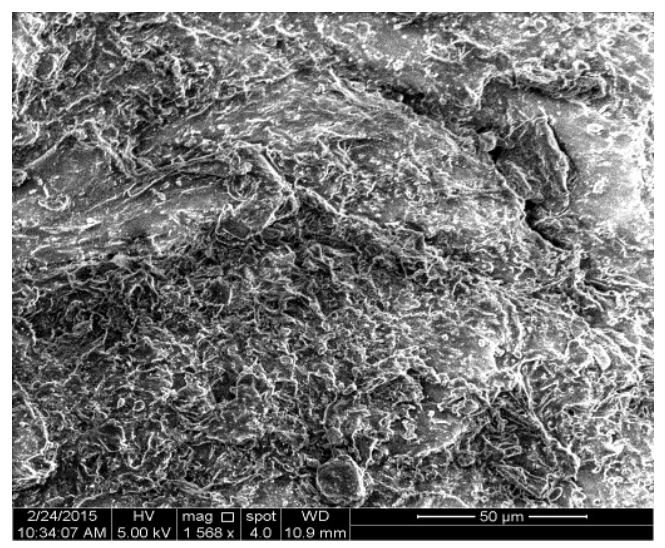

a

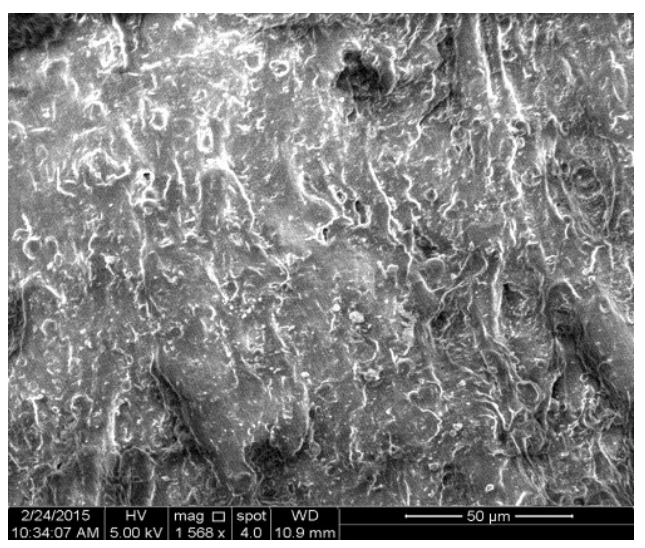

c

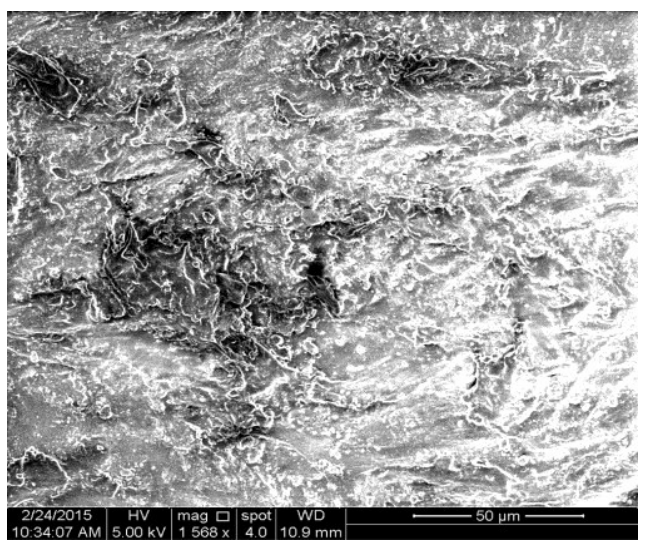

b

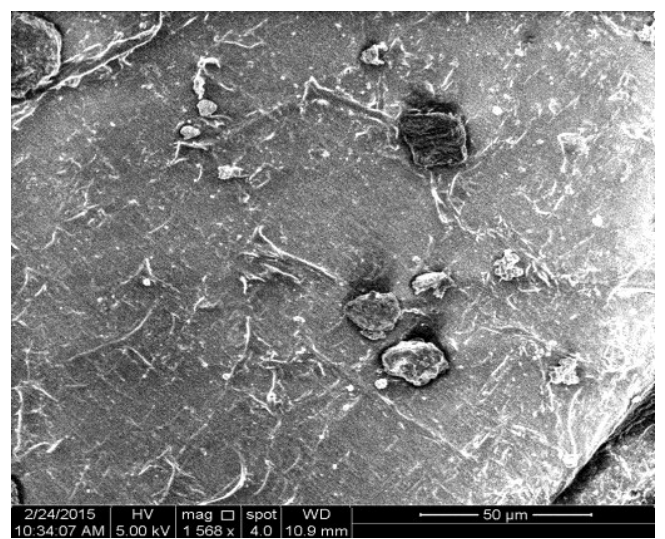

d 


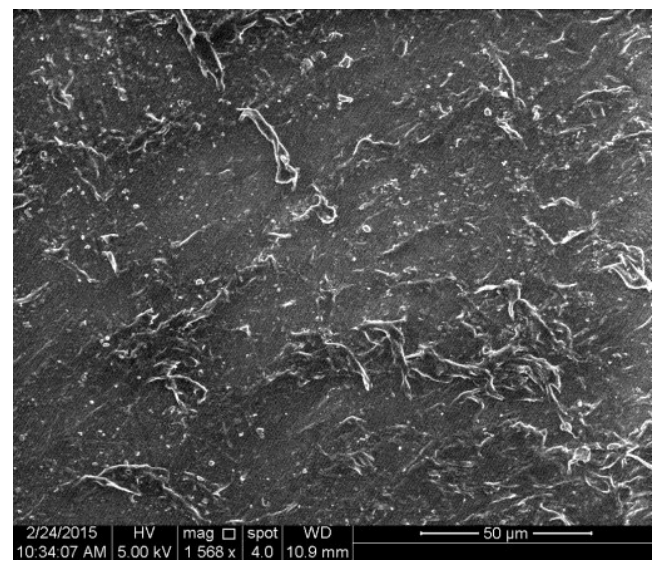

e

Figure (1): SEM images of (PP/PMMA/HDPE) polymer blends.(a):pure (PP/PMMA) (b):2\% wt HDPE, (c):4\% wt HDPE, (d):6\% wt HDPE, (e):8\% wt HDPE.

\section{FT-IR spectroscopic analysis}

FT-IR spectroscopy has been used to analyze the interactions among atoms or ions in (PP/PMMA/HDPE) blends. These interactions can induce changes in the vibrational modes of the blends. Figures (2,3,4,5 and 6) represents the FT-IR spectra of (PP/PMMA/HDPE) respectively, in the wave number range (500-4000) $\mathrm{cm}^{-1}$.In case of pure (PP/PMMA) figure (1), absorption packs sites show at (2950.32-2851.19) $\mathrm{cm}^{-1}$ is assigned to $\mathrm{C}-\mathrm{H}$ stretching vibrations indicating the presence of methylene and methyl groups, the wave number $1743.61 \mathrm{~cm}^{-1}$ correspond to $\mathrm{C}=\mathrm{O}$ stretching vibrations Of acetyl groups. but regarding absorption band at $1375.78 \mathrm{~cm}^{-1}$ arises due to Bending vibrations of $\mathrm{C}-\mathrm{O}$ groups and the absorption band at $1255.97 \mathrm{~cm}^{-1}$. It has been attributed to bending vibrations of $\mathrm{C}-\mathrm{O}$ groups[22,23,24]. The Fourier transforms infrared spectra of (PP/PMMA/HDPE) blends, with different ratio of HDPE are shown in figure (3,4,5 and 6). From the infrared spectra, it can be noticed that the variation of HDPE ratio causes some observable changes in the spectrum of (PP/PMMA/HDPE) within the same range of the wave number. It induces some new absorption bands and slight changes in the intensities of some absorption bands. The new absorption bands may be correlated, likewise to defects induced by the charge-transfer reaction between the polymer chains. This indicates the considerable not interaction between the three polymers.

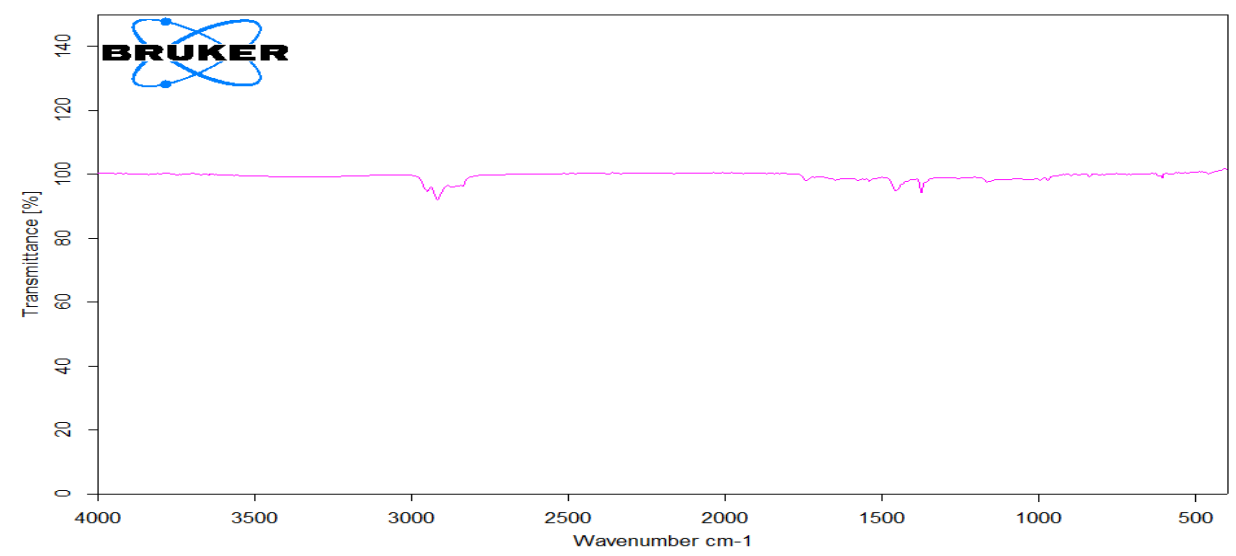

Figure (2): FT-IR spectra of (PP/PMMA) polymer blends. 


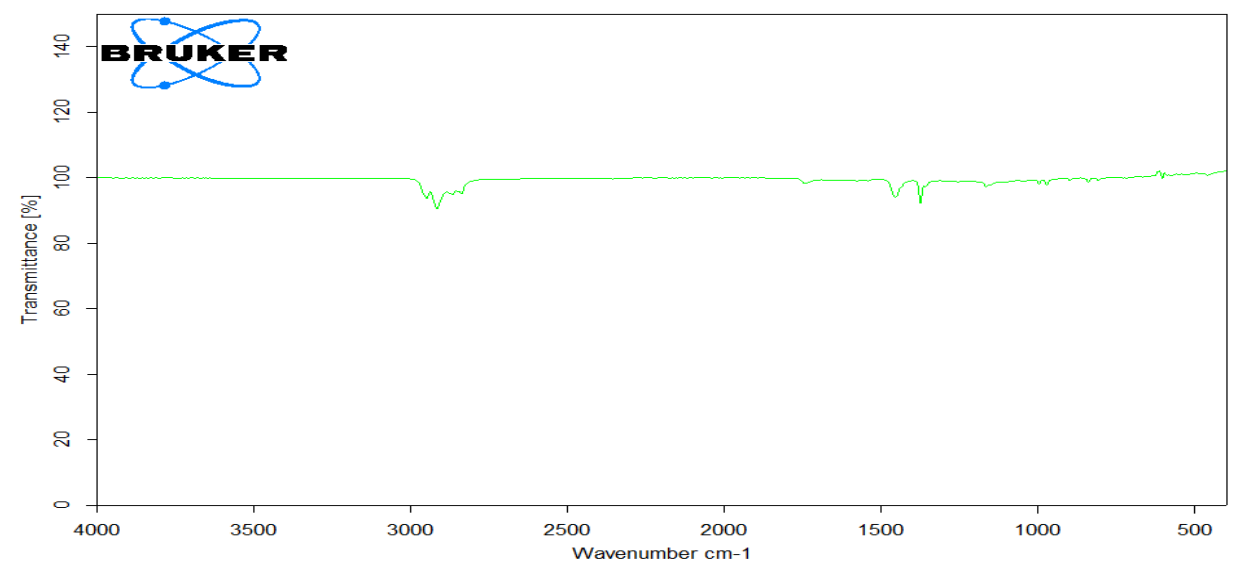

Figure (3): FT-IR spectra of (PP/PMMA/HDPE) polymer blends at 2\% wt

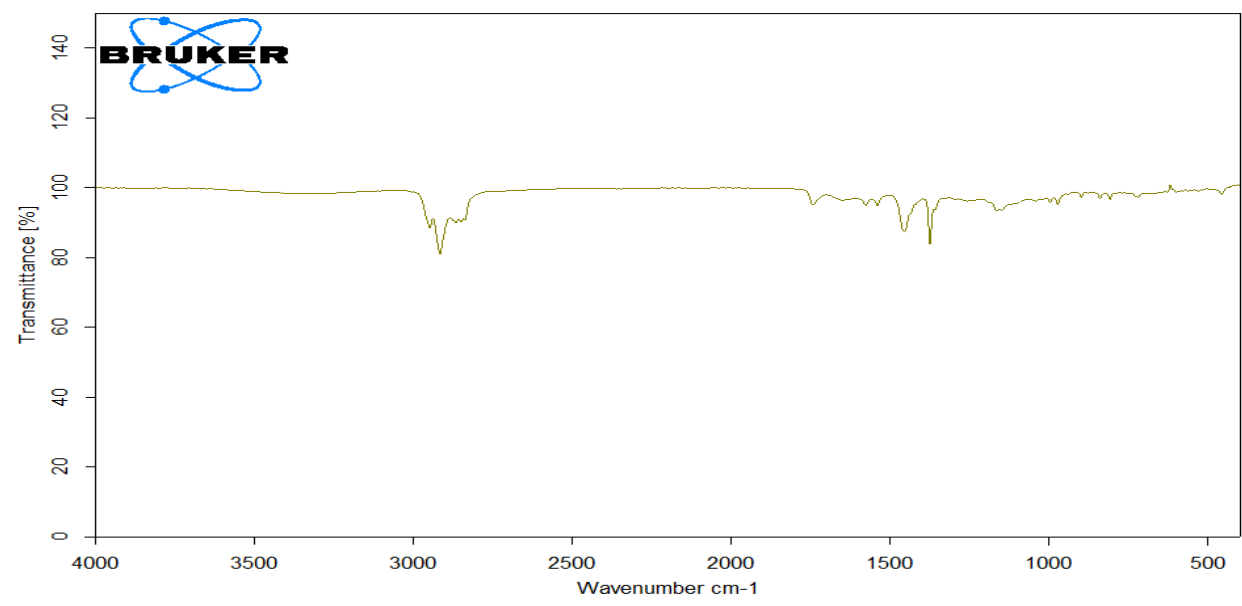

Figure (4): FT-IR spectra of (PP/PMMA/HDPE) polymer blends at 4\% wt

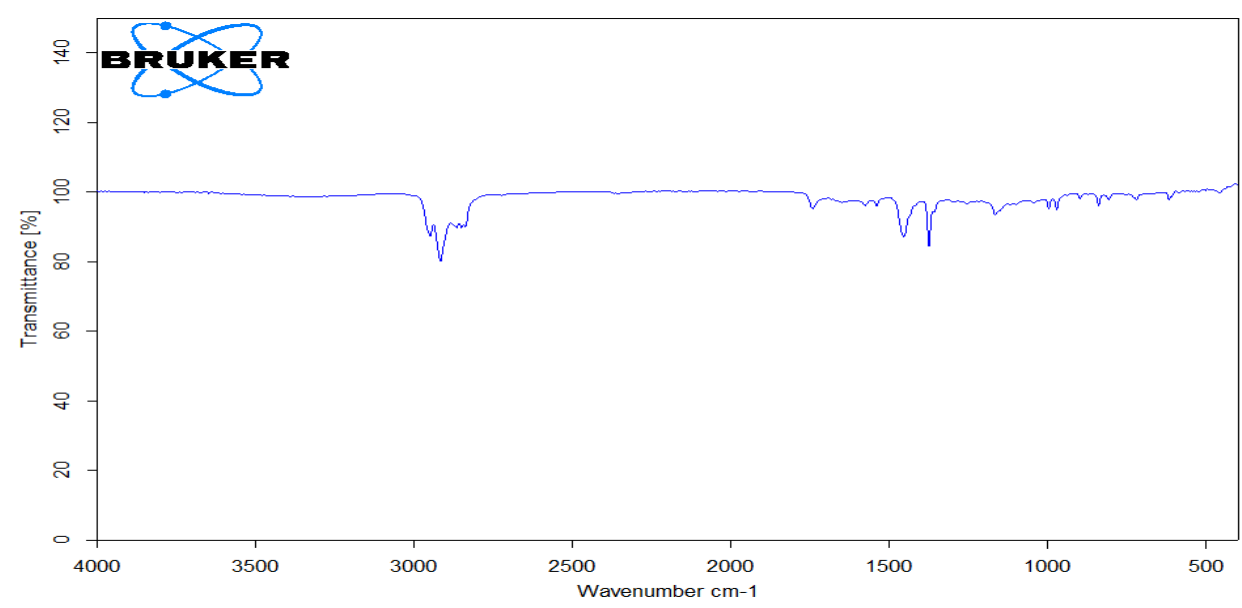

Figure (5): FT-IR spectra of (PP/PMMA/HDPE) polymer blends at $6 \% \mathrm{wt}$ 


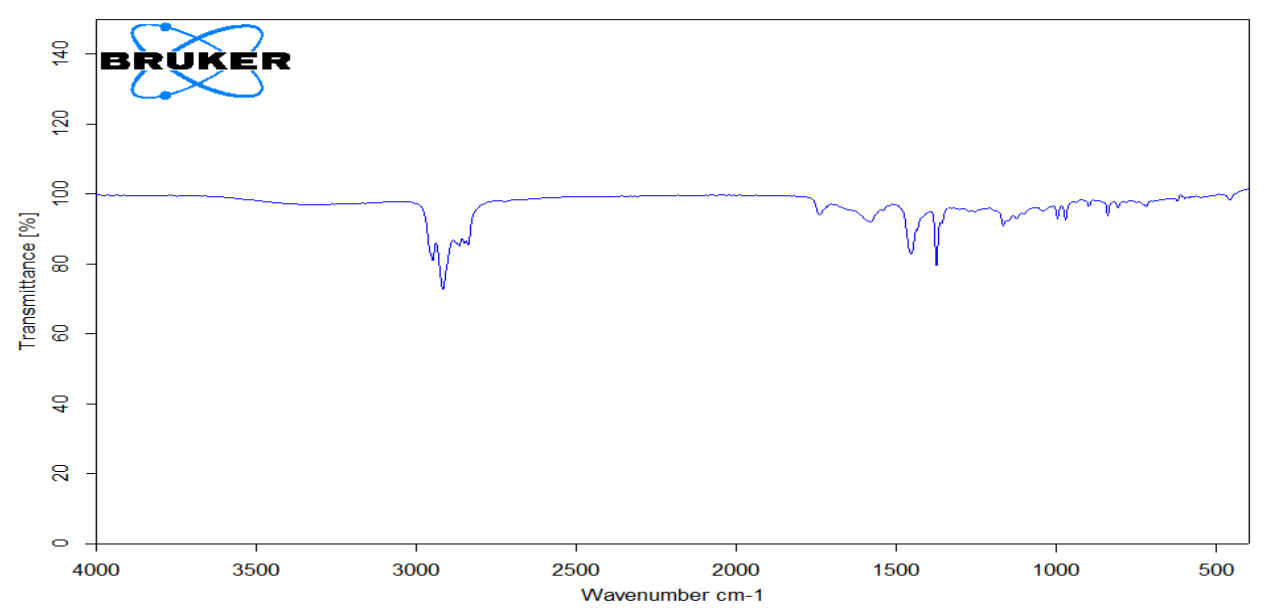

Figure (6): FT-IR spectra of (PP/PMMA/HDPE) polymer blends at $8 \% \mathrm{wt}$

\section{Optical Properties}

Figure (7) shows the absorbance spectra as function of the wavelength of the incident light for (PP/PMMA/HDPE) blend with different concentration of HDPE. It is clear that increasing the concentration of HDPE in the polymer blend leads to decreasing the peak intensity, and there is no any shift in the peak position for all amounts of the added material to the blend, that means there is no chemical interaction when added HDPE to the matrix and the decrement in the absorption is attributed to the decrement offshoot and tangles of polymeric chains, The fact that the linear high density polyethylene (unbranched)[25,26].

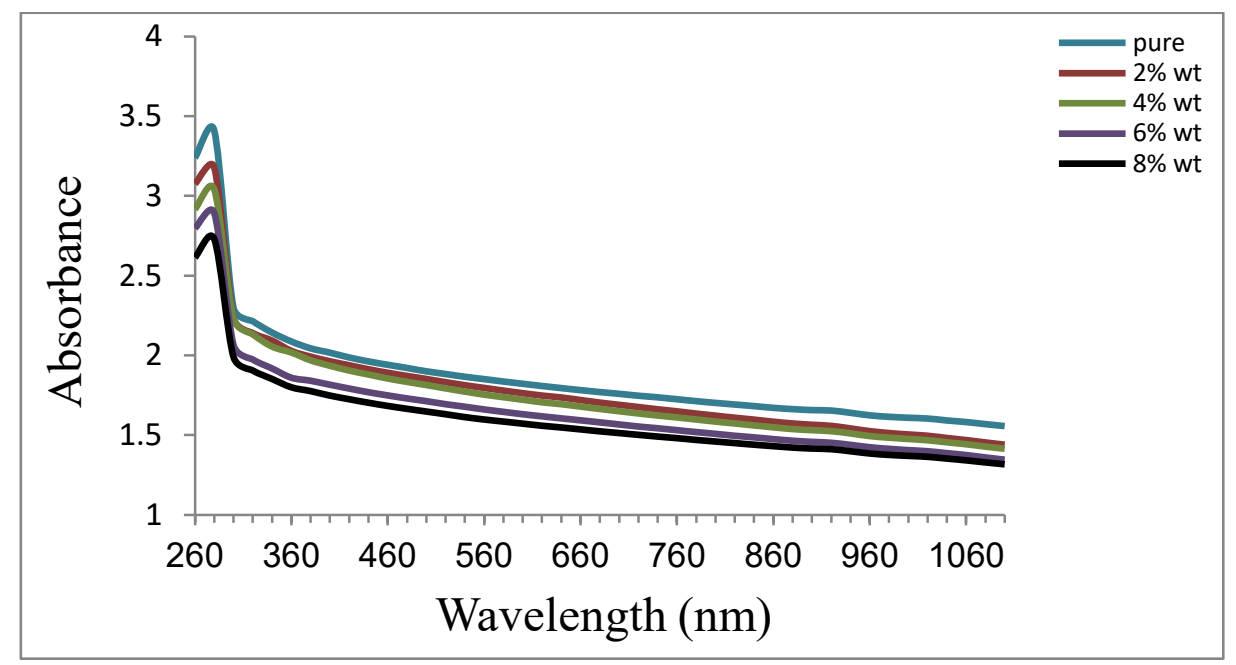

Figure (7): Absorbance spectra of (PP/PMMA/HDPE) blends as function of wavelength.

Figure (8) shows the optical transmittance spectra for (PP/PMMA/HDPE) blends as function of wavelength for several concentration of HDPE, the polymer transmittance increase with increasing the concentration of high density polyethylene this is due to added (HDPE), which leads to decrease positional planers in the forbidden energy gap, which leads to increased transmittance [27]. 


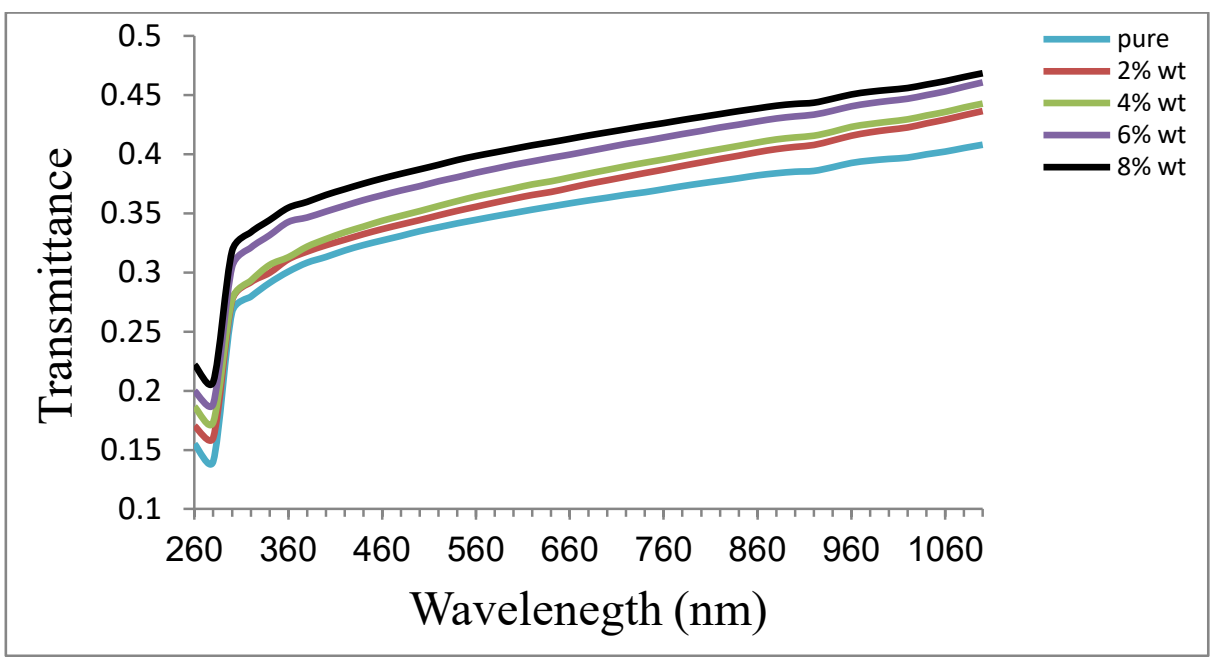

Figure (8): Transmittance spectra of (PP/PMMA/HDPE) blends as a function of wavelength.

The absorption coefficient $(\alpha)$ is calculated using equation (4). Figure (9) shows the absorption coefficient as a function of the photon energy, it can be noted that absorption is relatively small at low energy. This means that the possibility of electron transition is low, because the energy of the incident photon is not sufficient to move the electron from the valence band to the conduction band $\left(h v<E_{g}\right)$. The value of absorption coefficient is less than $10^{4} \mathrm{~cm}^{-1}$ at low energies, it is expected that indirect transition of electron occurs [28].

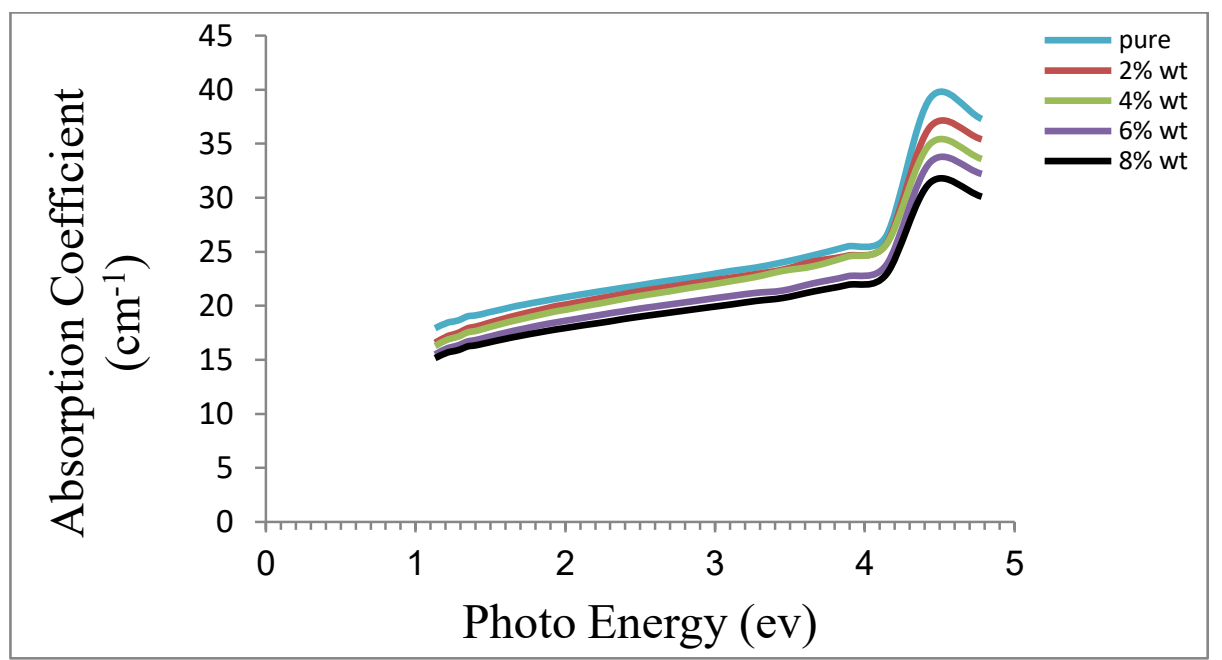

Figure (9): Absorption coefficient of (PP/PMMA/HDPE) blends as a function of photon energy.

Figure (10) shows the relationship between absorption edges $(\alpha h v)^{1 / 2}$ for (PP/PMMA/HDPE) blends as a function of photon energy. At extension of the curve to the values of $(\alpha h v)^{1 / 2}=0$, we get indirect allowed gap transition.From figure (11), we see that the values of energy gap increase with increase of the weight percentage of HDPE. This was due to the decrease of the site levels in forbidden indirect energy gap between the valence and conduction bands. It leads to increase the width of the optical energy gap with the increase in the concentration of highdensity polyethylene[29,30]. 

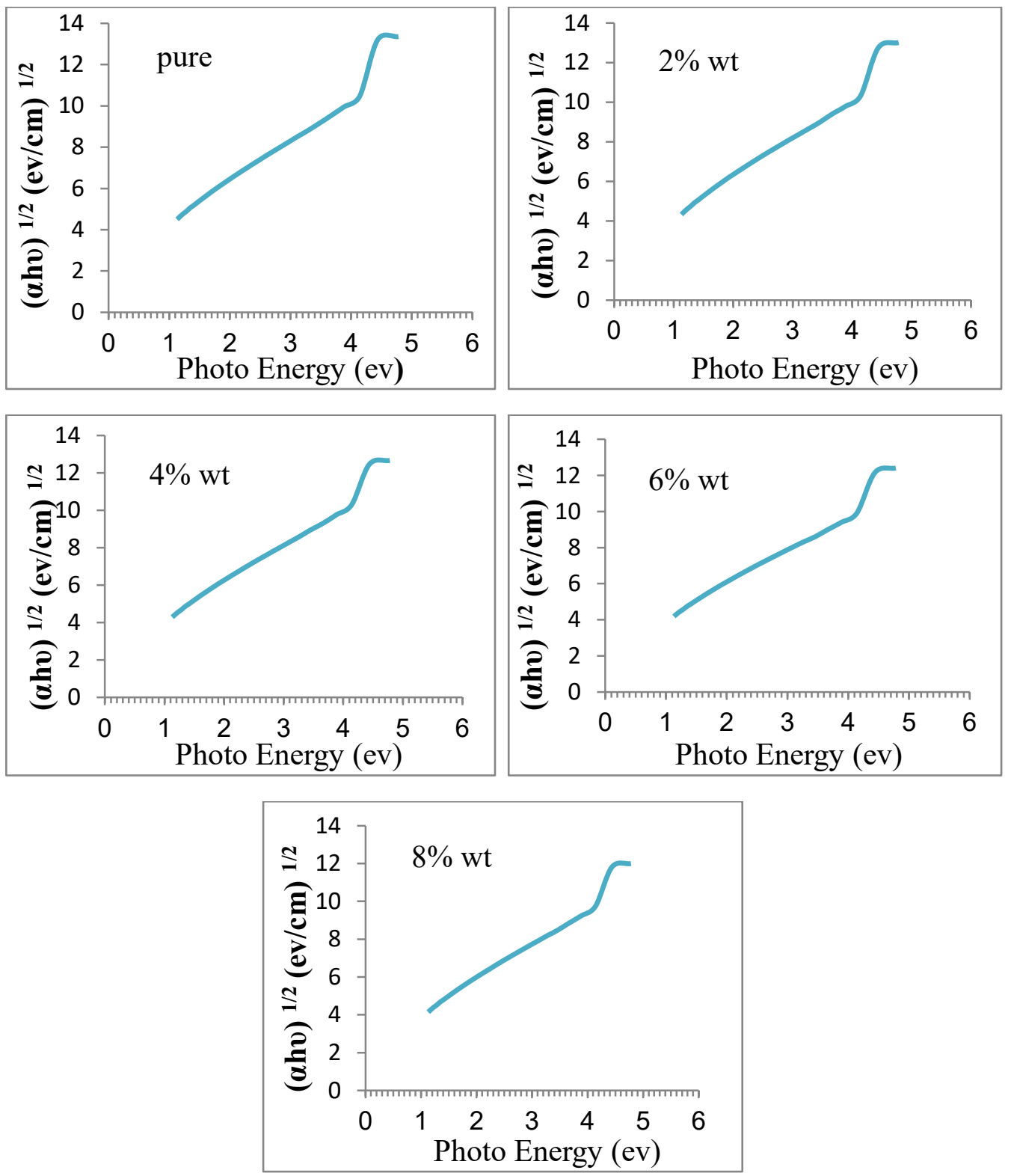

Figure (10): Energy gap of allowed indirect transition $(\alpha h v)^{1 / 2}$ of (PP/PMMA/HDPE) blends. 

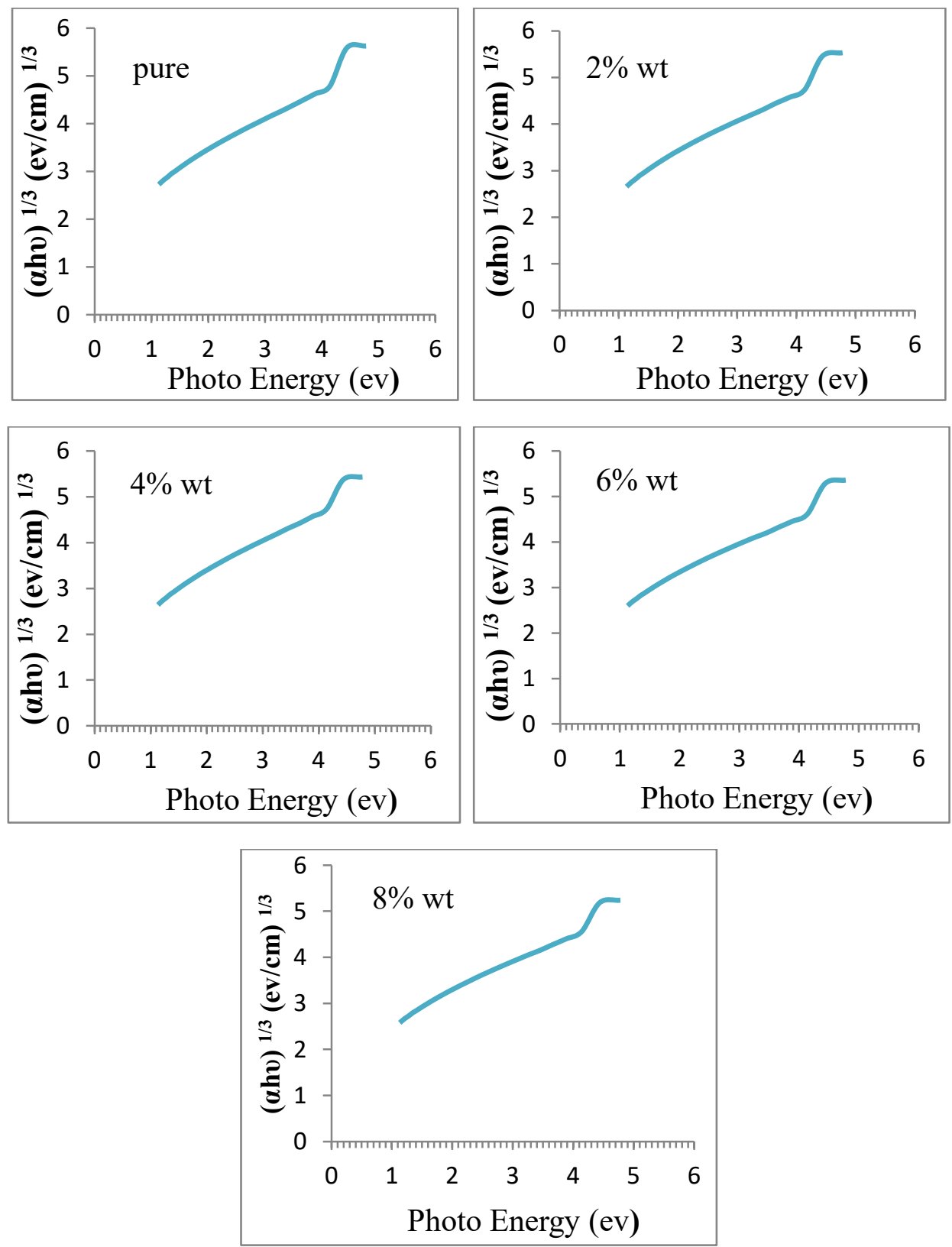

Figure (11): Energy gap of forbidden indirect transition $(\alpha h v)^{1 / 3}$ of (PP/PMMA/HDPE) blends.

Figure (12) describes the change in refraction index for (PP/PMMA/HDPE) as a function of wavelength, from this figure we can see increase refractive index values with increase in the concentration of HDPE, so as to increase the density of polymer mixtures, added to the fact that a high degree of crystallization, in other words, the High-density polyethylene molecules more Packed than it is amorphous polymer molecules. Also the values of the refractive index increases with increase the wavelength of a photon incident was due to a scattering of photons falling on the material[31]. 


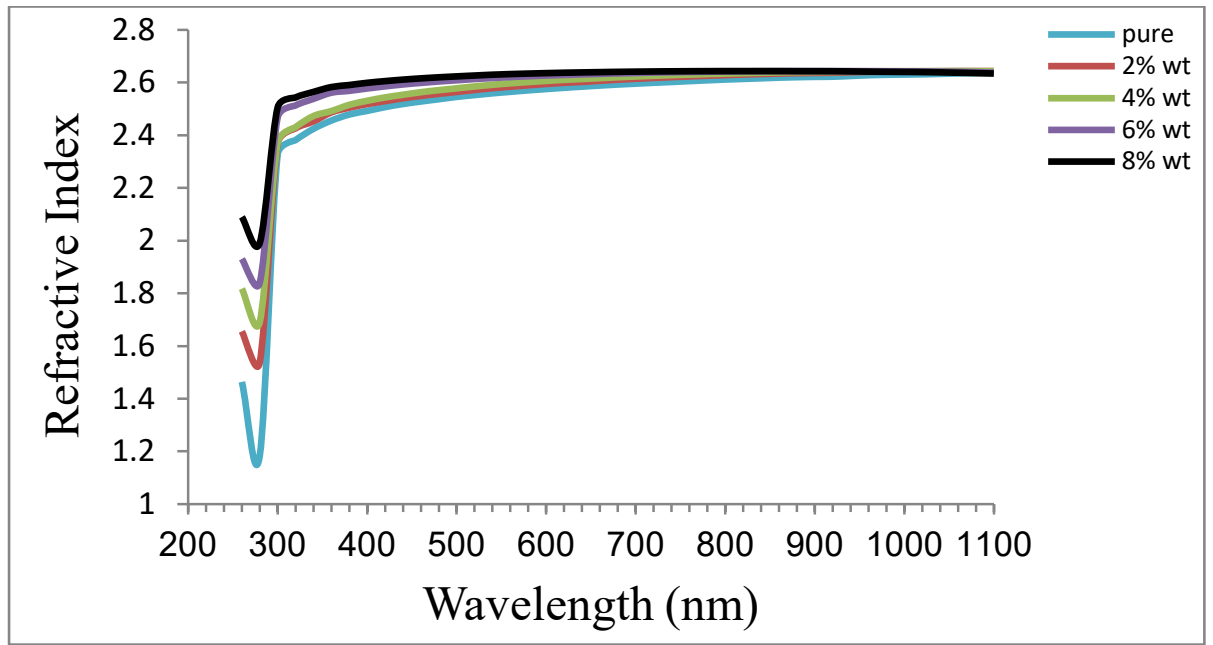

Figure (12): Refraction index of (PP/PMMA/HDPE) blends as a function wavelength.

The change of extinction coefficient as a function of wavelength is shown in Figure (13). It was noted that $\left(\mathrm{k}_{\mathrm{o}}\right)$ has lower value in the ultraviolet region and large increase in the visible spectrum region and lasts until the spectrum near-infrared region, the extinction coefficient decrease with increase in concentration of high-density polyethylene, and this is attributed to decrease in the absorption coefficient.

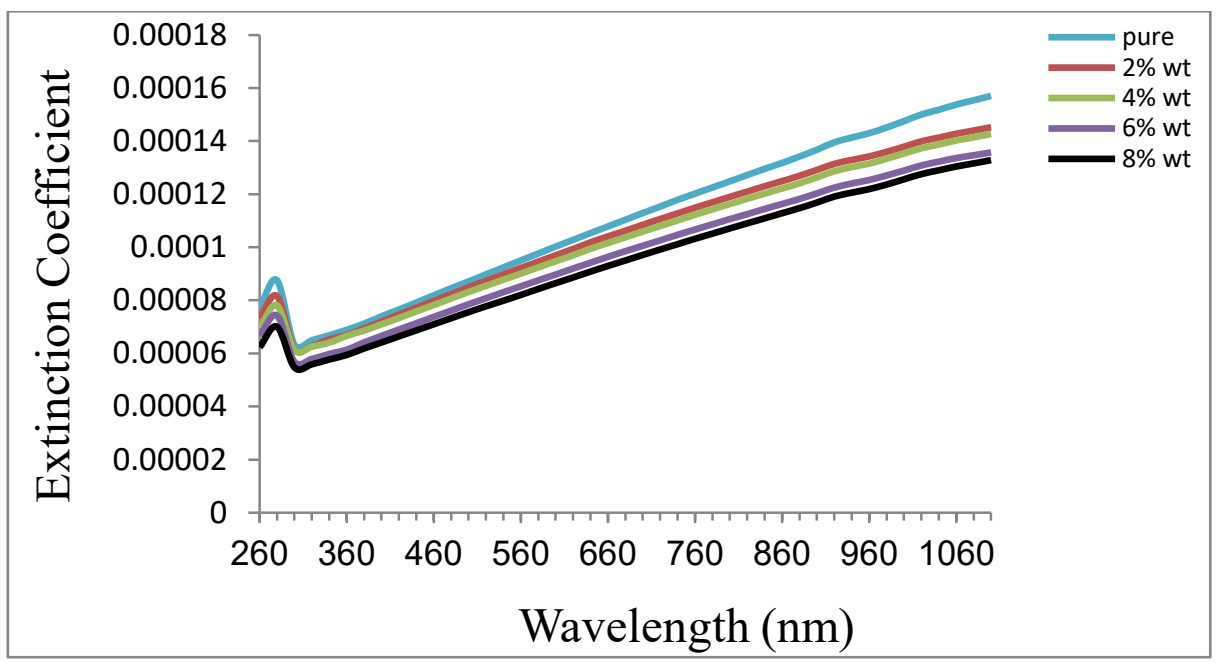

Figure (13): Extinction coefficient of (PP/PMMA/HDPE) blends as a function wavelength.

The real dielectric constant behavior with wavelength and change the added concentration shown in figure (14), have the same behavior for refractive index (n) and that depends on (n) according to equation (12) where very few extinction coefficient than refractive index can be neglected. but the imaginary dielectric behavior with wavelength and change the concentration of high-density polyethylene shown in figure (15). It is similar to the extinction coefficient and refractive index, the imaginary dielectric depends on $(\mathrm{k})$ and $(\mathrm{n})$ according to equation (13). 


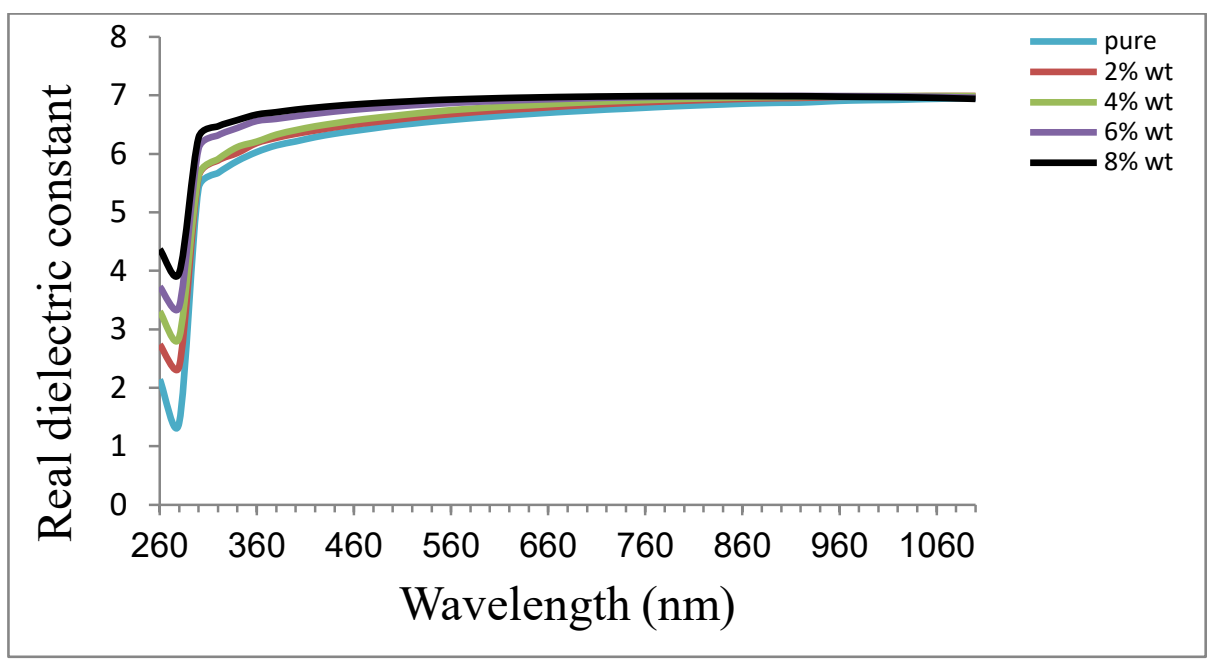

Figure (14): Real dielectric constant of (PP/PMMA/HDPE) as a function wavelength.

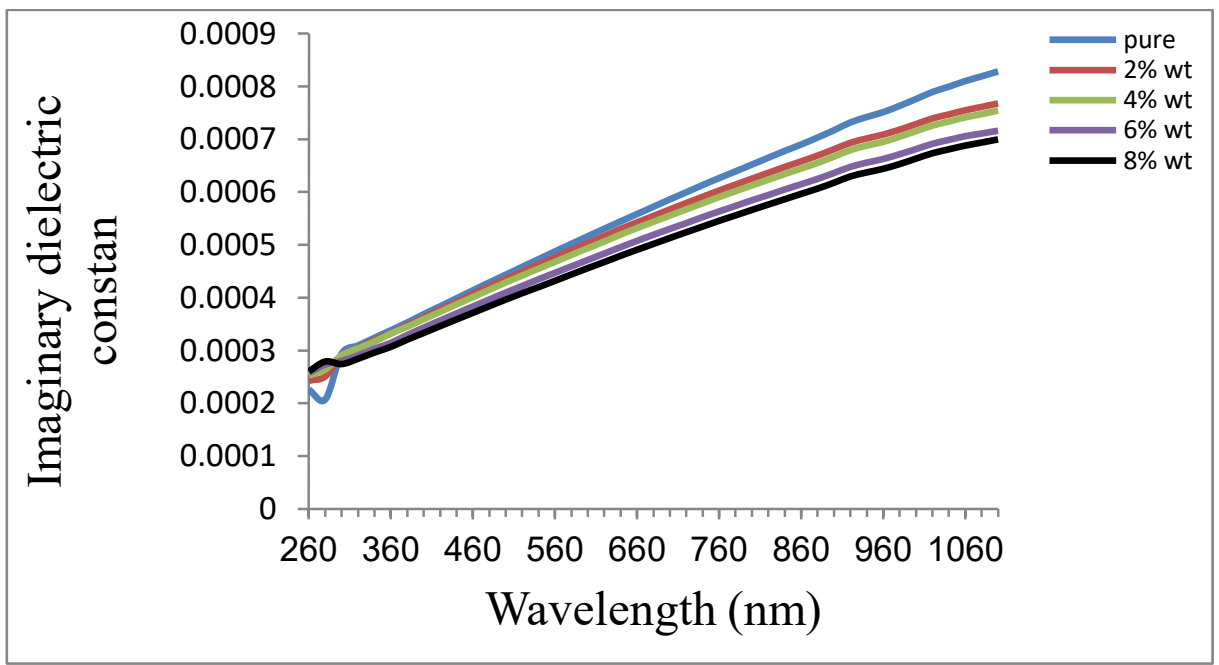

Figure (15): Imaginary dielectric constant of (PP/PMMA/HDPE) as a function wavelength.

\section{CONCLUSIONS}

In this study, scanning electron microscope image analysis showed the blends of (PP/PMMA/HDPE) have a high degree of compatibilizer. FT-IR scanning of the blends showed no change in the wavenumbers of the functional groups, which support the formation of (PP/PMMA/HDPE) physical blends, as well as the energy gap of indirect allowed and forbidden transition increases with increasing the concentration of high density Polyethylene, finally real dielectric constant increasing with increase the concentration of high density Polyethylene, but the imaginary dielectric constant decreases with increasing added. 


\section{References}

[1] A.k.Gupta and G.k.sah,"Miscibility Studies of PC/PMMA blends in Tetrahydrofuran by Viscometry,FTIR and SEM analysis",Nanosystems:Physics, Chemistry,Mathematics,4(5),670$679,(2013)$.

[2] J.Arutchelvi, M.Sudhakar, A.Arkatkar, M.Doble, S.Bhaduri, and P.V. Uppara,"Biodegradation of polyethylene and polypropylene",Indian Journal of Biotechnology, 7,9-22, (2008).

[3] B.A.Ibrahim, and K.M.Kadum, "Influence of Polymer Blending on Mechanical and Thermal Properties",Modern Applied Science,4,No 9,(2010).

[4] A.M.John, and L.H.Sperling,"Polymer Blends and Composites”,Plenum, NewYork,(1976).

[5] J.W.Barlow and D.R. Paul,"Polymer Engineering and Science”,21,No.15,985 - 996,(1981).

[6] B.M.H.Martinez, E.R.Vargas, F.J.M.Rodrequez, and R.C.Garcia,“Compatibility mechanisms between EVA and complex impact heterophasic PP-EPxcopolymers as a function of EP content",European Polymer Journal, 41,519 - 525,(2005).

[7] Y. Liu, adM. Kontopoulou,"The structure and physical properties of polypropylene and thermoplastic olefin nanocomposites containing nanosilic", Polymer,47,7723-7731,(2006).

[8] W.Hong, H.J.Woo, H.W.Choi, Y.S.Kim, and G.D.Kim,"Optical Property Modification of PMMA by Ion-beam Implantation”,Appl.Surd, Sci. 169 - 170,428 - 432,(2001).

[9] P.B.Johnson and R.W.Christy,“Optical Constants of Noble Metals”,Physical Review B,16,4370 $-4379,(1972)$.

[10] I.PROSYČEVAS, J.PUIŠO, A.GUOBIENĖ, S.TAMULEVIČIUS and R. NAUJOKAITIS, "Investigation of Silver Polymer Nanocomposites",Materials Science (MEDŽIAGOTYRA, 13, No.3,(2007).

[11] N.Raghupathi, and P.K.Mallick, “Long Fiber Thermoplastic Composites”, Newman's .Hinser, Pub., Munich,(1990).

[12] S.C.Sharma "Plastics, Design\& Processes",Standard Publisher's Distributors, Delhi, 1st Ed,(2004).

[13] R.V.Milby,"Plastics Technology”,Associate Professor losangeles Trade-Technical College NewYork, McGraw-Hill,(1973).

[14] H.J. Jonh, “Modern Plastics Encyclopedia”,McGraw - Hill, Inc., New York,(1998).

[15] N.J.Saleh and N.A.Mohammed, "The Effect of Blending of Linear Low Density Polyethylene on Mechanical Properties of High Density Polyethylene",Eng.and Tech.Journal,27,No.3,(2009).

[16] Y.N.Al-Jamal,“Solid State Physics”,Al-Mosel University,(2nd Ed.),Arabic Version,(2000).

[17] A.N.Donald, "Semiconductor Physics and Devices", Irwin, USA,(1992).

[18] B.G.Stereeman,"Solid State Electronic Devices" 2nd Ed, Practice Hall, Inc. Engle wood Cliffs, N.J.(1980).

[19] M.A.Khashan and A.M.El-Naggar,“Optics Communications”, Elsevier, 174, 445,(2000).

[20] I.B.Bertmun, “Handbook of Fluorescence Spectraof Aromatic Molecules”, Academic Press, New York,(1965). 
[21] C.Kittel,“Introduction to solid state physics”, 5th Ed., Willy, New York,(1981).

[22] R.M.Sealegrstein, J.k.B.Los Altos, "Diagnosis spectroscopy of organic compounds", 4th Ed, part one,(1981).

[23] C.H.Lee, T.L.Wu, Y.L.Chen and J.H.Wu,"Characteristics and discrimination of five types of woodplasticcomposites by FTIR spectroscopy combined with principal component analysis"Holzforschung,64,699-704,(2010).

[24] G.S.Ahmed, M.Gilbert, S.Mainprize and M.Rogerson,"FTIR analysis of silane grafted high density polyethylene"Plastics, Rubber and Composites,38 (1),13 - 20, (2009).

[25] J.Arutchelvi, M.Sudhakar, A.Arkatkar, M.Doble, S.Bhaduri, and P.V. Uppara,"Biodegradation of polyethylene and polypropylene",Indian Journal of Biotechnology, 7,9-22,(2008).

[26] T.K.Hamad,"Refractive Index Dispersion and Analysis of the Optical Parameters of (PMMA/PVA) Thin Film”,Journal of Al-Nahrain University,16(3),164-170, (2013).

[27] K.U.ISAH,“Optimization of process parameters of chemical bath deposition of (CdZnS) thin film”,Leonardo Journal of Sciences ,12,111-120,(2010).

[28] T.J.Alwan,“ Refractive Index Dispersion and Optical Properties of Dye Doped Polystyrene Films”,Malaysian Polymer Journal,5,No.2,204-213,(2010).

[29] M.Bedir, R.Kayali and M.Oztas, "Effect of the Zn concentration on the characteristic parameters ( ZnxCd1-XS) films developed by spraying phyrolysis method under the Nitrogen Atmosphere",Turk J Phys, 26,121-126,(2002).

[30] S.Jana, R.Thapa, R.Maity, and K.K. Chattopadhyay, “Optical and dielectric properties of PVA capped nanocrystalline $\mathrm{PbS}$ thin films synthesized by chemical bath deposition”,Physica E,40, 3121-3126, (2008).

[31] F.A.Mustafa, “Optical properties of NaI doped polyvinyl alcohol films”,Physical Sciences Research International,1(1),1-9, (2013). 